\title{
Paulo Emilio \\ e o estudo do Cinema
}

\section{ISMAII XAVIER}

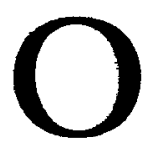

$s$ estudos e as pesquisas em nível universitário constituem um dado relativamente recente da cultura cinematográfica em quase todo o mundo. Em muitos países, foi na década de sessenta que a ampliação da cultura audiovisual e a ascensão do pólo comunicafóes na sociedade encontraram ressonância na academia. No entanto, a pesquisa do cinema tem tradiçăo própria, que vem das cinematecas ou mesmo de certo espírito de cineclube que data da segunda década do século.

A experiência brasileira seguiu este padrăo, com a presença de cineclubes nos anos 20, a fundaçáo da Cinemateca Brasileira, em São Paulo, nos anos 50, seguida da criação da Cinemateca do MAM do Rio de Janeiro. As universidades chegam ao cinema depois dos museus e, dentro delas, os estudantes se antecipam às suas Escolas. Tal é o caso do Clube de Cinema criado na Faculdade de Filosofia, Ciências e Letras, em 1940, como pólo de estudos e debates, dentro do espírito formador que marcou tais iniciativas desde o cinema mudo. Entre seus fundadores, a figura chave é Paulo Emilio Salles Gomes, o estudante de filosofia que trouxe para a Faculdade a melhor tradiçáo do cineclubismo - em temporada na França, tomou liçóes com Plinio Sussekind Rocha, exmembro do Chaplin-Club (1928-31), do Rio de Janeiro, principal foco da teoria cinematográfica do Brasil até então. O Clube de Cinema assinala o pólo da cinefilia na vida de Paulo Emilio e de seus amigos, dado que talvez não tivesse a importância que adquîriu não fosse contemporâneo de outra iniciativa, esta de maior alcance, do mesmo grupo de jovens da Faculdade: a criaçáo da revista de cultura Clima. Através desta, Paulo Emilio fez valer seu maior empenho e experiência no debate político, orientando pontos de vista, além de escrever seus artigos sobre cinema, contribuindo para ampliar o leque de intervençóes e estudos que deu especial relevo à Clima dentro da crítica brasileira, na literatura, no teatro, nas artes plásticas e no cinema. Nesse momento, começam a se configurar as indagaçóes do grupo no plano da história cultural, sua pergunta pela formaçăo dirigida aos vários setores da cultura brasileira, seu empenho em consolidar, no terreno do ensaio e da pesquisa erudita, um espírito de atualizaçáo herdado do Modernismo. 
Já neste período evidenciou-se a perspicácia de Paulo Emilio, a visão totalizante da conjuntura que sempre lhe permitiu pensar o cinema dentro da cultura, inserir a reflexão sobre a imagem nas questóes maiores do século. Mas seus vôos mais decisivos na interpretaçăo do fenômeno cinematográfico e das relaçóes entre história do cinema e cultura popular no Brasil ficaram adiados para os anos 50 e 60 . Nova permanência na França, entre 1946 e 1954, completou a formaçáo do crítico e revelou a maestria do biógrafo - vide os livros sobre Jean Vigo e Almereyda. $O$ contato estreito com a Cinemateca Francesa refinou o pesquisador.

De volta ao Brasil, consciente de que a presença de um arquivo de filmes era condiçáo para levar os 'estudos do cinema no Brasil a novo patamar, viabilizando pesquisas e a constituição de uma memória nacional, Paulo Emilio, juntamente com amigos militantes na crítica, como Almeida Salles, ou na USP, com Antonio Cândido, funda a Cinemateca Brasileira. Ganha impulso, a partir daí, o trabalho de pesquisa do cinema brasileiro, mas o salto maior nesta direçáo se dá nos anos 60 quando ocorre a articulação entre o esforço museológico e o trabalho universitário. Nesse sentido, se Paulo Emilio, como intelectual da geraçáo de Clima, é peça decisiva na afirmaçáo da Cinemateca como centro formador de pesquisadores em São Paulo, seu esforço de organização do campo se consolida quando seu estilo de trabalho encontra lugar na Universidade. Ou seja, quando o que se esboçara no Clube de Cinema como experiência de estudantes da Faculdade, ainda em pleno Estado Novo, a ela retorna, nos anos 60 , de Teoria Literária e Literatura Comparada. Convidado por Antonio Cândido, Paulo Emilio, a partir de 1966, orienta teses, forma pesquisadores atraídos de diferentes campos das ciências humanas e das letras. Seu poder aglutinador dá vida à pesquisa cinematográfica na USP antes que esta formalize o cinema como esfera acadêmica.

Destaco aqui os aspectos de ressonância institucional da ação de Paulo Emilio, ciente de que tal registro apenas nos dá uma pálida imagem da sua liderança, do seu estilo de açăo, do impacto do crítico sobre seus contemporâneos, do professor sobre seus alunos e colegas, seja na Universidade de Brasília, quando da implantaçáo da revolucionária experiência interrompida pelo regime militar em 1965, seja na USP, em sua FFCL ou no curso de cinema da Escola de Comunicaçóes e Artes criado em 1967. A par da força extraordinária de sua escrita que, cada vez mais, nos encanta e esclarece, Paulo Emilio é presença porque marcou de forma notável todos os que o conheceram. Singularidade que seus amigos de Clima captaram e expressaram como ninguém ao traçar o seu perfil (1). 
Conhecimento, sensibilidade política e rara personalidade permitiram ao intelectual empenhado na articulaçăo da pesquisa em nível nacional, esforço de atençâo às situaçóes concretas de que resultaram as sínteses mais argutas de que dispomos, sínteses que, partindo do cinema, iluminaram aspectos fundamentais da cultura e da,formação social brasileiras. Neste sentido, o que devemos a Paulo Emilio e a seus amigos da Faculdade é a afirmaçáo de um espírito de pesquisa ao mesmo tempo rigoroso e isento de compartimentaçóes estreitas, capaz de definir um projeto de longo alcance que fez convergir inclinaçóes particulares para uma investigaçáo compreensiva da cultura em sua relaçáo mais equili-

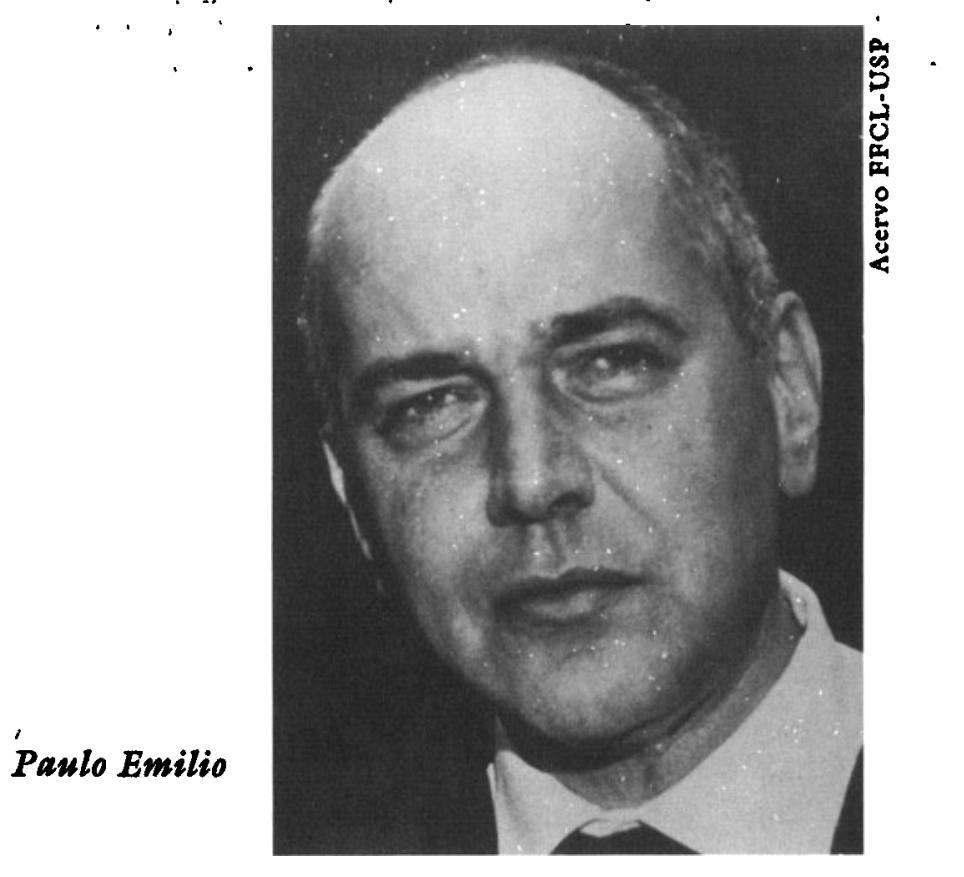

brada entre os diferentes aspectos do trabalho intelectual - história, crítica e teoria. E creio ter evitado, naqueles que formou ao longo dos anos, o teoricismo, as adesóes apressadas à moda, criando, pelo contrário, uma tradiçáo própria capaz de conferir maior organicidade aos trabalhos, num processo em que as novas geraçóes têm procurado fazer jus àquela paireno pelo concreto apontada por Gilda de Mello e Souza como o traço por excelência de Paulo Emilio.

O crítico de cinema de maior envergadura que o Brasil já teve define um capítulo da história da Faculdade de Filosofia que assinala, por sua vez, a contribuiçáo desta aos estudos do cinema. Com a criaçáo 
da ECA, o trabalho de Paulo Emilio e de pesquisadores formados na Cinemateca e na própria Faculdade orientou a implantaçáo de um departamento que, no plano da pesquisa, dentre suas várias linhas, tem destacado um trabalho que dá continuidade à experiência iniciada na área de Teoria Literária.

\section{Nota}

1 Ver os textos de Antonio Cándido, Décio de Almeida Prado e Ruy Coelho no livro Paulo Emilio: intelectual na linha de frente, organizado por Carlos Augusto Calil $e$ Maria Teresa Machado (São Paulo, Brasiliense/Embrafilme, 1986) e o texto de Gilda de Mello e Souza, Paulo Emilio: a crítica como perícia in $O$ Baile das quatro artes excorctcios de loitzura (São Paulo, Livraria Duas Cidades, 1980).

Imail Xapier é professor do Departamento de Cinema da Escola de Comunicaçoóes e Artes da USP. 